\title{
MUCINOUS ADENOCARCINOMA WITH ADENOMYOMATOSIS IN A PORCELAIN GALL BLADDER: A CASE REPORT
}

\author{
Kalpana Chandra ${ }^{1}$, Hema Pant ${ }^{2}$
}

\section{HOW TO CITE THIS ARTICLE:}

Kalpana Chandra, Hema Pant. "Mucinous adenocarcinoma with adenomyomatosis in a porcelain gall bladder: a case report". Journal of Evolution of Medical and Dental Sciences 2013; Vol2, Issue 31, August 5; Page: 57285732.

ABSTRACT: Adenocarcinoma accounts for 75 - $85 \%$ cases of primary carcinoma of gall bladder. The mucinous adenocarcinoma is a very common primary malignant neoplasm of GI tract, but this histological variant is nonexistent in gall bladder. Porcelain gall bladder is another rare finding in routine cholecystectomy specimen and regarded as precancerous lesion. We present a case of 50 years old female who came to OPD for yellowish discoloration of sclera and itching all over the body for three months. On USG there was a hetero echoic lesion approximately $3.8 \mathrm{~cm} \times 2.7$ in the neck region of gall bladder suggestive of gall bladder mass. The histological examination showed moderately differentiated mucinous adenocarcinoma with Adenomyomatosis in a porcelain gall bladder.

KEYWORDS: mucinous adenocarcinoma, porcelain gall bladder, adenomyomatosis.

INTRODUCTION: Mucinous adenocarcinoma of gall bladder is a rare tumor with very few case reports in literature .The findings of porcelain gallbladder with adenomyomatosis is an extremely rare association with it. Mucinous adenocarcinoma accounts for $5-11 \%$ in reported series ${ }^{1,2}$, and 3 . It is usually well differentiated and is generally noted for their lack of distant metastasis. This tumor is characterized by abundant extracellular mucin pool with scattered detached tumor cells.

CASE REPORT: A 50 years old female presented with a history of yellowish discoloration of the sclera and itching all over the body for three months which was insidious in onset and gradually progressive .It was associated with clay colored stool, high colored urine, loss of appetite and loss of weight. There was history of fever which was intermittent, moderate in intensity and was associated with chills and rigors. Physical examination revealed a firm mass about $2 \mathrm{~cm}$ below the costal margins about $5 \times 3 \mathrm{~cm}$, globular and moving with respiration. Laboratory investigation showed $\mathrm{Hb}$ 12gm\%, TLC-15,200/cu mm, DLC, N-67\%, L-26\%, E01\%, M 06\%. Liver functions showed total bilirubin $17.7 \mathrm{mg} / \mathrm{dl}$, direct bilirubin $-12.7 \mathrm{mg} / \mathrm{dl}$, indirect bilirubin $5 \mathrm{mg} / \mathrm{dl}, \mathrm{PT}-15 /$ control-15 and APTT-Test 34.1/control-32. The ultrasonography showed thickened and irregular gall bladder wall with multiple calculi of $10-18 \mathrm{~mm}$ in the lumen. A heteroechoic lesion of size approximately $3.8 \times 2.7$ is seen in the gall bladder neck region suggestive of gall bladder mass. With preoperative diagnosis of gall bladder mass, only simple cholecystectomy was performed as patient's relatives were not willing for extensive surgery because of money constraints .Per-operative hard growth in Hartman's pouch was noted which was extending into the lumen of the gall bladder. There was no evidence of regional metastasis, ascites, or lymph node in the porta, peri choledochal, retro- portal or celiac area. The resected specimen of gall bladder measured $8 \times 4 \mathrm{~cm}$ with wall thickness varies from 0.3 to 0.6 $\mathrm{cm}$. There was a polypoidal mass measuring $2.5 \times 2.0 \mathrm{~cm}$ in the neck region of gall bladder. The cut surface of the mass was firm, solid, tan yellow with gelatinous texture with tan white to yellow, 
smooth and shiny mucosa. Small multiples stones were also present in the lumen of gall bladder. No lymph node is identified. Microscopy showed infiltrative moderately differentiated adenocarcinoma with abundant extracellular mucin comprising more than $50 \%$ with mucin lakes formation focally and detached free floating malignant cells. At the periphery, there was a well defined area of glandular hyperplasia with no atypia. The gall bladder in another area showed denuded mucosa and thickening of muscular layer with diffuse mononuclear cell infiltration and spotty area of calcification. The presence of mucin was confirmed by PAS stain. Tumor cells were strongly immunoreactive for pancytokeratin (CK) and EMA. Based on this diagnosis of moderately differentiated mucinous adenocarcinoma with adenomyomatosis in a porcelain gall bladder was made.

DISCUSSION: Gall bladder cancer is the $5^{\text {th }}$ most common gastrointestinal malignancy 4 . This is a disease of old age with a peak incidence occurring at 70-79 years of age and female: male ratio is 3:1. However, mucinous adenocarcinoma accounts for only $5 \%$ of all carcinomas in gall bladder meeting the criteria of more than $50 \%$ of extracellular mucin. There are two histological variants; one variant is characterized by neoplastic glands distended with mucin and lined by columnar cells with mild to moderate nuclear atypia. The second variant is characterized by small group or clusters of cells surrounded by abundant mucin. Both patterns can coexist in the same tumour. In majority of cases mucinous adenocarcinoma is frequently well differentiated and admixed with conventional adenocarcinoma but poorly differentiated mucinous adenocarcinoma with distant metastasis has also been reported 5 . One of the most frequently implicated predisposing factors in development of carcinoma gall bladder is cholelithiasis.

Porcelain gall bladder meaning calcified gall bladder is a rare but significant late complication of gall stone with a low incidence of $0.06-0.86 \%$ in cholecystectomy specimen 6 . The term "porcelain gallbladder" was coined in 1929 to describe the bluish discoloration and brittle consistency of a gallbladder with an extensively calcified wall. The pathogenesis of gall bladder calcification remains controversial, but the vast majority of specimens have concurrent cholelithiasis, leading authors to suggest that porcelain gallbladder is an unusual manifestation of chronic cholecystitis. The incidence of cancer arising within a porcelain gall bladder as previously reported in the literature was high but modern series have shown a much lower incidence 5-10 \%. On the basis of the calcification pattern, Porcelain gallbladder has been classified as complete and incomplete type. The complete type shows broad and continuous bands of calcification in the muscularis propria. The incomplete type shows multiple, punctuate calcifications. The overall incidence of gallbladder cancer with selective wall calcification was approximately $7 \%$ and no cancer was found in the complete type ${ }^{7}$. Based on this observation it was suggested that the two types of calcification are associated with different cancer risks. The association of mucinous adenocarcinoma with porcelain gall bladder is another rare finding ${ }^{8}$.

Adenomyomatosis usually causes no symptoms and is an incidental finding. On rare occasion adenocarcinoma of the gall bladder has been found occurring in the same region where gall bladder wall is involved with adenomyomatosis. But this association has been thought to be coincidental rather than casual ${ }^{9}$.

In summary, we present a rare histological variant of moderately differentiated mucinous adenocarcinoma as a primary neoplasm of gall bladder and its association with adenomyomatosis 


\section{CASE REPORT}

and selective wall calcification. This case is being reported because of infrequent histological findings in the same specimen.

ACKNOWLEDGEMENT: The authors are highly thankful to Departments of Surgery, Department of Pathology and Department of Radiology of SRMS-IMS, Bareilly for providing adequate facilities for working on this study.

The authors are also thankful to The Dean SRMS-IMS, Bareilly for permitting us to publish this case report.

No financial sources or funding involved in the formation of manuscript.

No potential financial conflicts of interest.

\section{REFERENCES:-}

1. Rogers L F, Lastra M P, Lin K T, et al. Calcifying mucinous adenocarcinoma of the gall bladder. Am J Gastroenterol 1973; 59:441-445?

2. Piehler J M, Crichlow RW. Primary carcinoma of the gallbladder. Surg Gynecol Obstet 1978; 147:929-942.

3. Shani M, Hart J, Modan B. Cancer of the biliary system: a study of 445 cases. Br J Surg 1974; 61:98-100.

4. Landis SA, Murra T, Bolden S. Wingo PA. Cancer statistics. CA Cancer J Clin1999; 49:8-31.

5. Paul W. Brandt-Rauf and A. Whitley Branwood. An Unusual Case of Gallbladder Cancer in an Automotive Worker. CA Cancer J Clin1980;30:333-336

6. Polk HC., Jr Carcinoma and the calcified gall bladder. Gastroenterology 1966; 50:582-585.

7. Stephen AE, Berger DL. Carcinoma in the porcelain gallbladder: a relationship revisited.Surgery2001; 129:699-703.

8. Joo YE, Kim HS, Choi SK, Rew JS, Kim HJ, Kang HK, et al. Case of mucinous adenocarcinoma with porcelain gallbladder. J Gastroenterol Hepatol. 2003; 18: 995-998.

9. Keith D.L., Taylor A. S. Tumour of the gall bladder, bile duct and ampulla. In Feldman M, Freidman LS and Sleisenger MH, editors. Sleisenger and Fordtran's - Gastro enterointestinal and Liver disease: pathophysiology, diagnosis, management.

London: Saunder LTD, Philadelphia; 2002 ch 60, pp 1153-1164, 2002. 


\section{CASE REPORT}

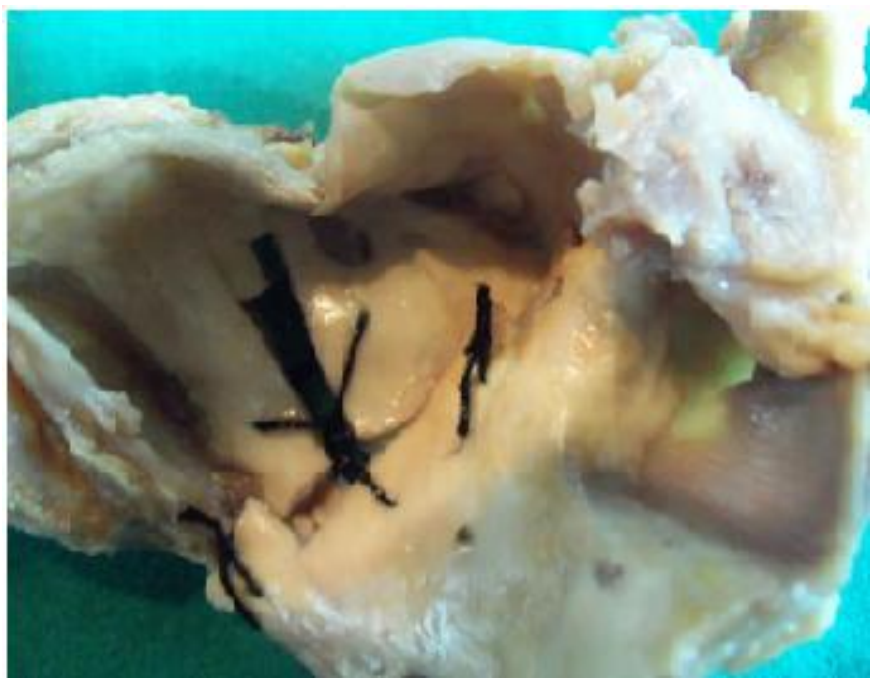

Fig.1:- Gross: opened up porcelain gall bladder With a polypoidal mass in the neck region

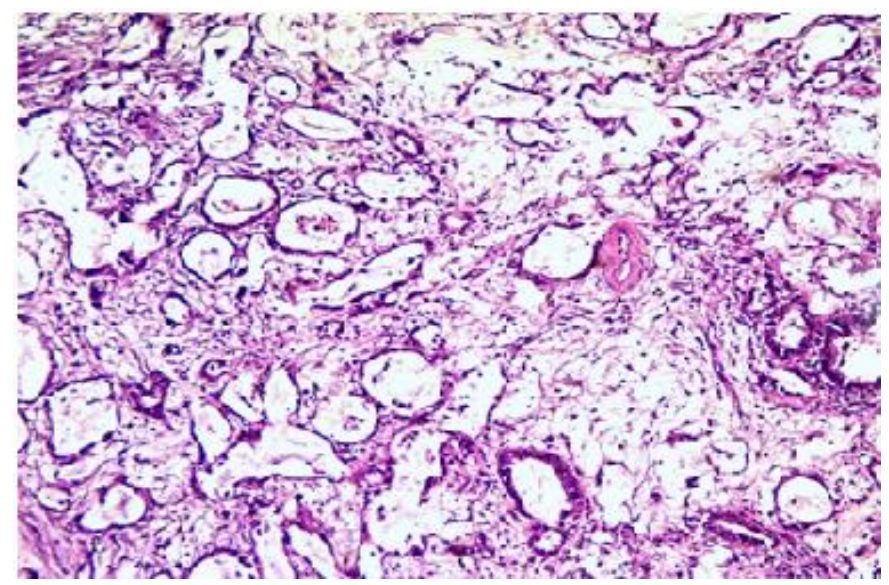

Fig.2:- Mucinous adenocarcinoma with mucin lakes (H\&E 5X)

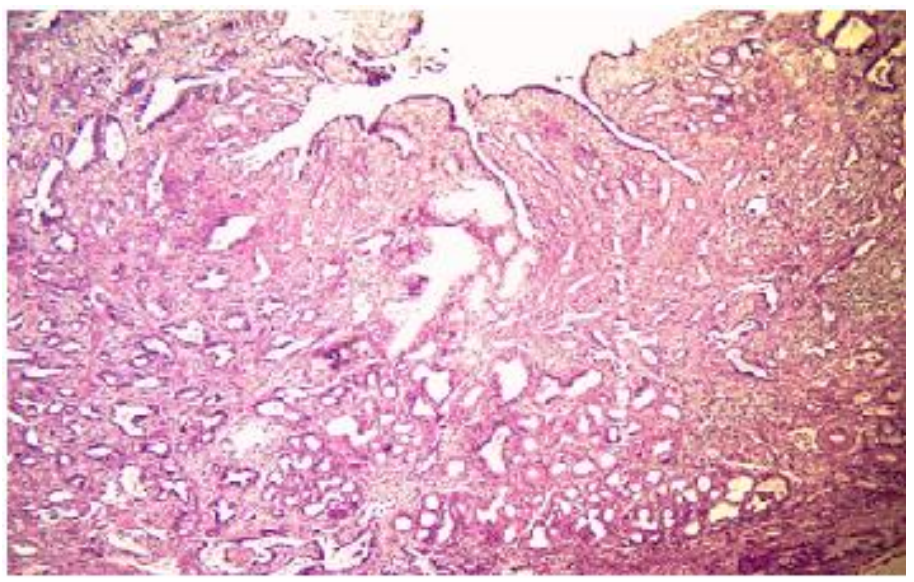

Fig.3:- Rokitansky-Aschoff Sinuses with adenomyomatosis (H \& E 5X) 


\section{CASE REPORT}

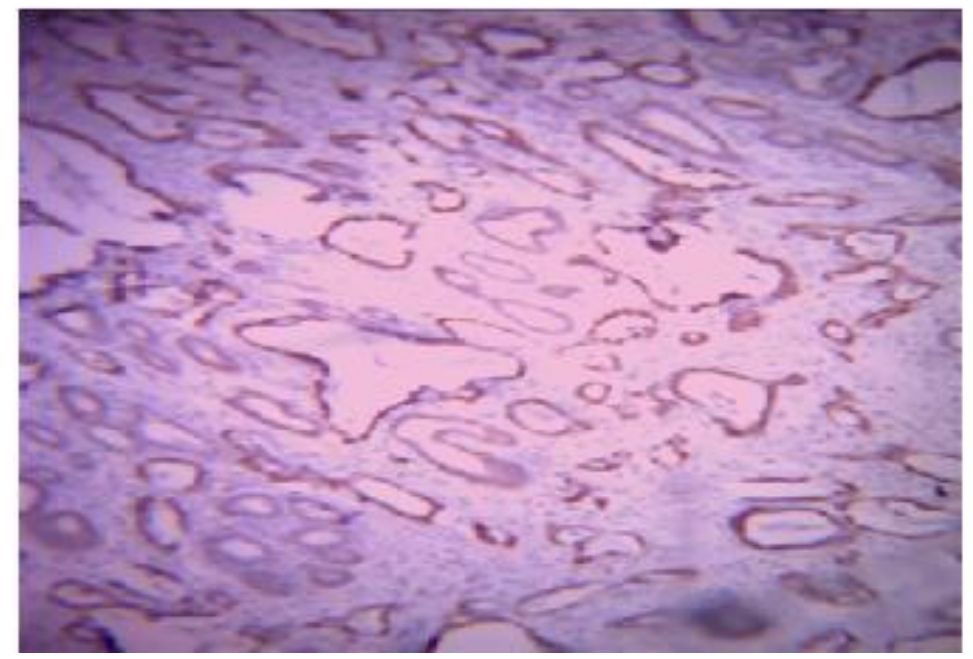

Fig.4:- Micro photograph showing a positive

reaction to EMA Immunostain (10X).

\section{AUTHORS:}

1. Kalpana Chandra

2. Hema Pant

\section{PARTICULARS OF CONTRIBUTORS}

1. Associate Professor, Department of Pathology, Shri Ram Murti Smarak Institute of Medicine Science, Bhojipura, Bareilly, UP.

2. Associate Professor, Department of Pathology, Shri Ram Murti Smarak Institute of Medicine Science, Bhojipura, Bareilly, UP.

\section{NAME ADRRESS EMAIL ID OF THE} CORRESPONDING AUTHOR:

Dr. Kalpana Chandra,

Associate Professor,

Department of Pathology,

Shri Ram Murti Smarak Institute of Medicine

Science, Bhojipura,

Bareilly, Uttar Pradesh - 243202.

Email - kalpana_chandra_14@yahoo.co.in

Date of Submission: 12/07/2013.

Date of Peer Review: 12/07/2013.

Date of Acceptance: 26/07/2013.

Date of Publishing: 31/07/2013 